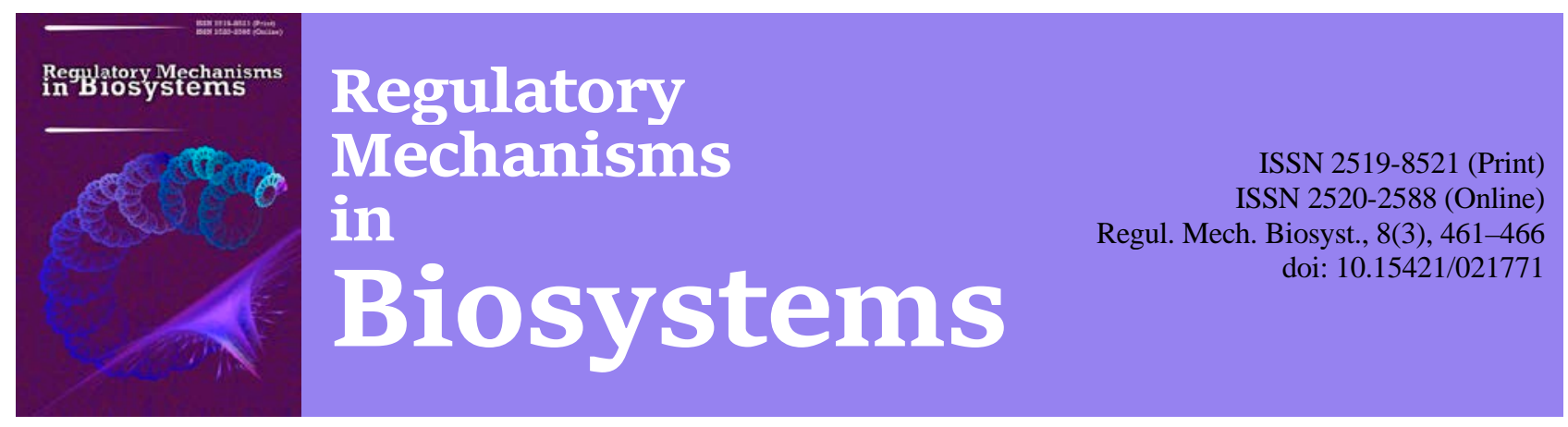

\title{
Molecular mechanisms of aluminium ions neurotoxicity in brain cells of fish from various pelagic areas
}

\author{
E. V. Sukharenko*, I. V. Samoylova*, V. S. Nedzvetsky*,** \\ *Bingöl University, Bingöl, Turkey \\ **Oles Honchar Dnipro National University, Dnipro, Ukraine
}

Article info

Received 29.06.2017

Received in revised form 20.07.2017

Accepted 27.07.2017

Bingol University,

Selahaddin-i Eyyubi Mah.

Aydinlık Cad., 12000,

Bingöl, Turkey,

E-mail: helenasuhar@gmail.com samoylovairina2014@gmail.com

Oles Honchar Dnipro National University, Gagarin Ave., 72, Dnipro, 49010, Ukraine.

Tel.: +38-056-760-84-38

E-mail:

nedzvetskyvictor@gmail.com
Sukharenko, E. V., Samoylova, I. V., \& Nedzvetsky, V. S. (2017). Molecular mechanisms of aluminium ions neurotoxicity in brain cells of fish from various pelagic areas. Regulatory Mechanisms in Biosystems, 8(3), 461-466. doi: 10.15421/021771

Neurotoxic effects of aluminum chloride in higher than usual environment concentration $(10 \mathrm{mg} / \mathrm{L})$ were studied in brains of fishes from various pelagic areas, especially in sunfish (Lepomis macrochirus Rafinesque, 1819), roach (Rutilus rutilus Linnaeus, 1758), crucian carp (Carasius carasius Linnaeus, 1758), goby (Neogobius fluviatilis Pallas, 1811). The intensity of oxidative stress and the content of both cytoskeleton protein GFAP and cytosol Ca-binding protein $\mathrm{S} 100 \beta$ were determined. The differences in oxidative stress data were observed in the liver and brain of fish during 45 days of treatment with aluminum chloride. The data indicated that in the modeling of aluminum intoxication in mature adult fishes the level of oxidative stress was noticeably higher in the brain than in the liver. This index was lower by1.5-2.0 times on average in the liver cells than in the brain. The obtained data evidently demonstrate high sensitivity to aluminum ions in neural tissue cells of fish from various pelagic areas. Chronic intoxication with aluminum ions induced intense astrogliosis in the fish brain. Astrogliosis was determined as result of overexpression of both cytoskeleton and cytosole markers of astrocytes - GFAP and protein S100 3 (on 75-112\% and 67-105\% accordingly). Moreover, it was shown that the neurotixic effect of aluminum ions is closely related to metabolism of astroglial intermediate filaments. The results of western blotting showed a considerable increase in the content of the lysis protein products of GFAP with a range of molecular weight from 40-49 $\mathrm{kDa}$. A similar metabolic disturbance was determined for the upregulation protein $\mathrm{S} 100 \beta$ expression and particularly in the increase in the content of polypeptide fragments of this protein with molecular weight $24-37 \mathrm{kDa}$. Thus, the obtained results allow one to presume that aluminum ions activate in the fish brain intracellular proteases which have a capacity to destroy the proteins of intermediate filaments. The data presented display the pronounced neurotoxic effect of mobile forms of aluminum on both expression level and the metabolism of molecular markers of astrocytes GFAP and protein S100ß. Aluminum ions induce integrated changes, the more important of which are a significant increase in final LPO products, an increase in antioxidant enzyme activity, a reactivation of glial cells in the brain. Integrated determination of the content and polypeptide fragments of specific astrocyte proteins in fishes brains coupled with oxidative stress data may be used as valid biomarkers of toxic pollutant effects in aquatic environments.

Keywords: aquatic organisms; oxidative stress; neurospecific proteins; glial fibrillary acidic protein; GFAP; protein S100 $\beta$

\section{Introduction}

Aluminum is the most common metal in nature. The number of minerals which consist of aluminum is more than 250, including aluminum silicates - compounds that make up about $82 \%$ of the earth's crust. Being one of the most common elements in the Earth's crust, aluminum is found in almost all natural water resources (Gostomski, 1990). It enters into these water areas by various ways: with partial dissolution of clays and aluminosilicates, with atmospheric precipitation, sewage, and industrial wastes (Walton et al., 2010; Liu et al., 2014; Aksu, 2015). Aluminum toxicity is a universal problem for all forms of organism. Since last decades of the XX century, ecologically significant concentrations of $\mathrm{Al}$ are have been intensively studied for natural water resources. The content of soluble forms of $\mathrm{Al}$ increases exponentially with decrease in $\mathrm{pH}$. However, the concentration of mobile organic forms of $\mathrm{Al}$ relates to concentration of organic acids in the water solution rather than $\mathrm{pH}$ (Driscoll, 1985; Sivakumar et al., 2012). At the same time, it has been hypothesized that $\mathrm{Al}$ is potentially toxic to aquatic organisms. A number of studies have confirmed the toxicity of aluminum ions for various aquatic species. Moreover, the US Environmental Protection Agency in August 1988 published a document on ambient water quality criteria, especially the toxicity of aluminum. Established criteria recommend that the one-hour average concentration of aluminum should not exceed $750 \mu \mathrm{g} / 1$ and four-day average concentration should not exceed $87 \mu \mathrm{g} / \mathrm{l}$. These criteria were developed by an acute toxicity study for 20 species of freshwater aquatic organisms. Two fish species, namely striped bass and brook trout, were determined to be the most sensitive to the toxic effects of aluminum among the species of North America (Gostomski, 1990). Without doubt, the toxicity of aluminum ions in the aquatic environment is extremely complex. Biological effects of aluminum are determined for a number of water quality characteristics, especially $\mathrm{pH}$, content of organic carbon and hardness (Trenfield et al., 2012; Cardwell et al., 2017).

One important factor for aluminum toxicity is mobility of $\mathrm{Al}^{3+}$ ions. It has been shown that in marine diatoms dissolved aluminum has a differences in toxic effect compared with precipitated aluminum forms. Aluminum toxicity is multifaceted. The genotoxic potential of 
aluminum ions has been demonstrated for embryonic zebrafish cells $\mathrm{ZF}_{4}$. A few hours exposure induced double strand breaks of DNA (Pereira et al., 2013). Modern toxicology considers the increased concentrations of aluminum ions to be the most dangerous among the "hidden" adverse environmental factors. The toxic effect of aluminum is associated with its antagonism with respect to calcium, magnesium, zinc, copper, and its ability to accumulate in animal tissues due to easy integration into the structure of proteins. The degree of aluminum accumulation in living organisms is limited by the insolubility of some of its natural compounds in water. However, due to the fact that insoluble aluminum compounds are solubilized in the acidic environment of the vertebrate stomach, the $\mathrm{Al}^{3+}$ content in the body rises. Higher than normal concentrations of aluminum ions in the organism provoke the development of various pathologies, caused mainly by a disorder of the oxidation-reduction balance of tissues (Nedzvetskii et al., 2006; Fernandez-Davila et al., 2012). With excessive concentrations of aluminum in the body of aquatic organisms, the target organs are kidneys, bones, and the central nervous system as usual. The reactions of the nervous system to aluminum intoxication are quite diverse. Neurotoxicity of aluminum may be accompanied by impaired glucose metabolism, cytoskeleton changes and modulation of signal transduction mechanisms (Singla et al., 2015). The studies in vivo and in vitro have shown that aluminum affects the formation of inositol phosphate. Some components of the inositol phosphate signal system, including proteins (phosphatidylinositol-specific phospholipase $\mathrm{C}$, protein kinase $\mathrm{C}$ and $\mathrm{G}$ protein) are extremely sensitive to the content of aluminum ions, which inhibit hydrolysis of phosphoinositol, resulting in the decreased level of inositol triphosphate $\left(\mathrm{IP}_{3}\right)$ and release of $\mathrm{Ca}^{2+}$ ions from intracellular membrane storages (Sun et al., 2008). The specific toxicity of aluminum is associated with the ability of fish to secrete mucus intensively and accumulate ions of this metal in the gills. In this case, the effect of aluminum on the function of the gills of fish juveniles and fry is differentiated. The highest sensitivity was found in salmon fry; this fact may be explained by the insufficiently high antioxidant protection activity of fish in the early ontogenesis period (Grassie et al., 2013; Skilbrei et al., 2013). Despite the abundance of aluminum in the aquatic environment, the effects of aluminum intoxication on aquatic organisms have not been adequately studied. Neurotoxic effects of $\mathrm{Al}^{3+}$ have been studied in vivo in terrestrial animals; however, this neurotoxicity was not displayed for aquatic organisms in view of the vast scale of modern environmental pollution. In addition, anthropogenic pollution of water resources with aluminum compounds, inducing the decreased acidity of the environment, creates favorable conditions for the chronic growth of the aluminum content. Thus, the study of the biological effects of aluminum ions on the population of aquatic organisms is of current concern, primarily for industrial regions with developed electrical, aviation, chemical, and petroleum industries. Fish, as the last link in the trophic chain in water bodies, is a reliable and adequate indicator for the extent of anthropogenic pressure on aquatic ecosystems. This is due to their high sensitivity, wide distribution, and accessibility for studying the reactions of their organisms to various external affects.

Glial cell reactivity is one of the widest used biomarkers of neural tissue disorders (Tykhomyrov et al., 2016). The upregulation of glial fibrillary acidic protein (GFAP) expression in astrocytes is an obligatory molecular event that accompanies cell response in neural tissue against toxic chemicals and different damages (Nedzvetskii et al., 2012). This phenomenon is termed astroglisis and occurs in the brains of all kind of vertebrates. Several kinds of fish could be more sensitive to aluminium ions toxicity. Thus, the study of astrogliosis can elucidate common molecular mechanisms of cell reactivity and individual characteristics of fishes from various pelagic areas.

\section{Materials and methods}

In accordance with the generally accepted research methods, sunfish, goby, crucian carp and roach fish specimens were taken from a conditionally clean area. The water area of the Vorskla River was chosen from within an existing ichthyological sanctuary, which is practically not subject to technogenic impact. The chronic effect of aluminum ions on the four fish species was studied over 45 days of their treatment with $10 \mathrm{mg} / \mathrm{l}$ of aluminum chloride. The stable concentration of aluminum ions was maintained by replacement $35 \%$ water containing $10 \mathrm{mg} / \mathrm{l}$ of aluminum chloride. Every group of fish species included 20 individuals from various pelagic areas: sunfish (Lepomis macrochirus Rafinesque, 1819), roach (Rutilus rutilus Linnaeus, 1758), crucian carp (Carasius carasius Linnaeus, 1758), goby (Neogobius fluviatilis Pallas, 1811). Adult fishes (3-5 years old, $\mathrm{n}=20$ ) were randomly divided into similar groups (control and experimental ones). The experimental groups of fish were kept in similar aquariums with 180 liters capacity. Control groups of all fish species were kept in aquariums with purified tap water. Every fish individual was phenotypically analyzed. The phenotype of fish was visually observed and the morphological exterior and interior characteristics were analyzed. The proportion of fish with different morphological and physiological aberrations was calculated. In order to sample the biological material, decapitation was applied in conformity with the technique used for treating small animals. After decapitation, the fish brain was homogenized (in the cold) in a 10-fold volume of $50 \mathrm{mM}$ Tris buffer $\mathrm{pH} 7.8$ containing $2 \mathrm{mM}$ ethylenediaminetetraacetate (EDTA), $1 \mathrm{mM}$ 2-mercaptoethanol, $0.1 \mathrm{mM}$ phenylmethylsulfonyl fluoride (PMSF) and $5 \mathrm{mM}$ soybean trypsin inhibitor. The homogenate was centrifuged for $50 \mathrm{~min}$ at $60,000 \mathrm{~g}$. After centrifugation, a fraction of the water-soluble proteins with supernatant was taken. To extract cytoskeletal proteins, a 4-fold volume of Tris buffer $\mathrm{pH} 7.8$ containing $4 \mathrm{M}$ urea was added to the pellet and resuspended to homogenate. Resuspended samples were incubated at $+4{ }^{\circ} \mathrm{C}$ for $60 \mathrm{~min}$ for extraction of cytoskeleton proteins. After extraction of insoluble proteins, the samples were centrifuged for $60 \mathrm{~min}$ at $60,000 \mathrm{~g}$ and a fraction of the water-insoluble proteins was taken. The samples of both soluble and insoluble proteins were separated by electrophoresis in a gradient of a polyacrylamide gel (7-18\%) with $0.1 \%$ sodium dodecyl sulfate (Nedzvetskiy et al., 2011). The content and polypeptide composition of glial intermediate filaments and $\mathrm{S} 100 \beta$ were assessed by immunoblotting using a polyclonal monospecific antiserums antiGFAP (Santa Cruz Biotechnology, USA, cat. no. sc-33673, dilution of 1 : 2000) and anti-S100 $\beta$ (Thermo Scientific, USA, cat. no. PA516257 , dilution of $1: 1000)$. The relative intensity of the colour densities of the polypeptide zones was detected by computer processing of the scanned immunoblotting results. Quantitative GFAP analysis was carried out by comparing the intensity of the colour of the relevant polypeptide zones between the experimental and control samples referred to the amount of total protein in the fractions. The content of total protein was estimated by Lowry's method in Miller's modification (Miller, 1959). The level of lipid peroxidation was measured using a LPO-586 test kit (Oxis, Int. Inc., USA) by a method based on the reaction of N-methyl-2-phenylindole with malonic dialdehyde and 4-hydroxyalkenes (Ohkawa, 1979). The obtained data were processed using mathematical statistics for small number of samples. The relative content of GFAP was expressed as the mean \pm standard error of the mean, a significant difference between the groups was assessed using the Student's t-test $(\mathrm{P}<0.05)$ after testing the hypotheses of the normal distribution and the difference between the general variances.

\section{Results and discussion}

All fish individuals were subject to complete biological analysis. Despite the fact that the anatomical and morphological analysis of the experimental and control groups of fish showed no abnormalities and deviations from healthy growth, while studying the intensity of oxidative stress in the liver and brain of gobies, crucian carp and roach from the experimental groups, it was established that the content of TBA-reactive products significantly increased. The number of TBA active products in the liver of individuals of the experimental groups was higher by $22-69 \%$ as compared with the groups of fish kept in the purified tap water (Table 1).

The increase in amount of the final products of lipid peroxidation in the liver of the mature adults under conditions of the aluminum 
contamination was significantly lower than the increase in the similar indicators in the brain of these individuals where the content of lipid degradation significantly exceeded the control values by $41-58 \%$ (Table 2).

Table 1

Content of TBA-active products in the liver of mature adult individuals under conditions of chronic contamination with aluminum ions (nmol/mg material)

\begin{tabular}{lcc}
\hline $\begin{array}{l}\text { Groups of fishes from } \\
\text { various pelagic areas }\end{array}$ & Control group & Experimental group \\
\hline Sunfish & $1.53 \pm 0.10$ & $1.93 \pm 0.12^{*}$ \\
Crucian carp & $1.32 \pm 0.11$ & $1.78 \pm 0.13^{*}$ \\
Goby & $1.78 \pm 0.12$ & $2.18 \pm 0.14^{*}$ \\
Roach & $1.34 \pm 0.09$ & $2.27 \pm 0.14^{* *}$ \\
\hline
\end{tabular}

Note: significance of the difference in comparison with the control $*-\mathrm{P}<$ $0.05, * *-\mathrm{P}<0.01$.

Table 2

Content of TBA-active products in the brain of mature adult individuals under conditions of chronic contamination with aluminum ions (nmol/mg material)

\begin{tabular}{lcc}
\hline $\begin{array}{l}\text { Groups of fishes from } \\
\text { various pelagic areas }\end{array}$ & Control group & Experimental group \\
\hline Sunfish & $2.32 \pm 0.13$ & $3.27 \pm 0.19^{* *}$ \\
Crucian carp & $1.92 \pm 0.11$ & $2.89 \pm 0.20^{* *}$ \\
Goby & $2.81 \pm 0.12$ & $3.95 \pm 0.18^{* *}$ \\
Roach & $1.89 \pm 0.16$ & $2.98 \pm 0.23^{* *}$ \\
\hline
\end{tabular}

Note: see Table 1.

The maximum increase in the content of the LPO end products in the brain of mature adults with chronic exposure to $\mathrm{Al}^{3+}$ ions was found in the brain of the roach group (on an average $58.0 \%$ higher than the control values), slightly lower oxidative stress indices were observed in the brains of mature adults of experimental carp groups (51\%), sun fish (an average of $41 \%$ ), and goby (an average of $41 \%$ ). In the liver of mature adults of the experimental groups of crucian carp, goby, sun fish, the generation of oxidative stress relative to the control groups of fish was less intense compared to the brain, respecttively an average of $35 \%, 22 \%$, and $26 \%(\mathrm{P}<0.05)$.

An exception was formed by individuals of the experimental group of common roach, in which the intensity of oxidative processes in the liver increased by an average of $69 \%(\mathrm{P}<0.01)$, and it was comparable to the intensity of these processes in the brain of the experimental animals. The activity of the antioxidant system enzyme - superoxide dismutase (SOD) is one of earliest responses to oxidative stress in the cells. The increase of SOD activity was determined in all fish species treated with aluminum ions. Exposure to aluminum ions induced the same increase of SOD activity in the brains of all studied fish species (Fig. 1).

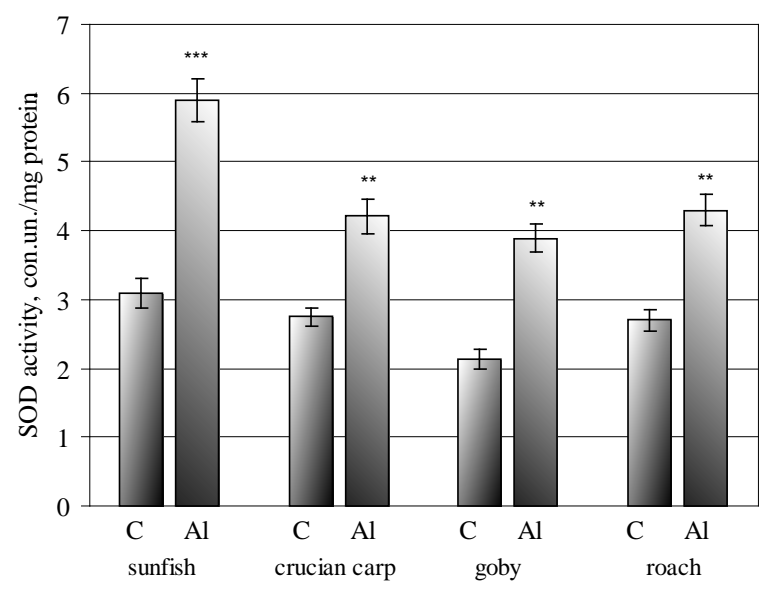

Fig. 1. SOD activity in the liver of sunfish, crucian carp, goby and roach groups treated with aluminum ions $(\mathrm{Al})$ compared to control groups of fish (C): ** $-\mathrm{P}<0.01$, $* * *-\mathrm{P}<0.001$ significance of differences in comparison with the control
SOD activity in the samples of sunfish liver was found to be almost 2.0 times greater than in the control group. Therefore, the increase in SOD activity of about 1.6 times in the samples from crucian carp wasn't so meaningful but this difference was still significant $\mathrm{P}<0.01$ (Fig. 2). More intensive growth of SOD activity in the liver tissue could relate to higher level of antioxidant protection of the liver cells compared to brain cells. The results of the research make it possible to assert that it is the nervous tissue of fish, due to the significant content of polyunsaturated fatty acids and high level of oxygen utilization (about 1/5 of total consumption), that is most susceptible to oxidative action. Therefore, oxidative damage of this type of tissue can be considered as the most probable mechanism of realization of toxic effects of aluminum ions.

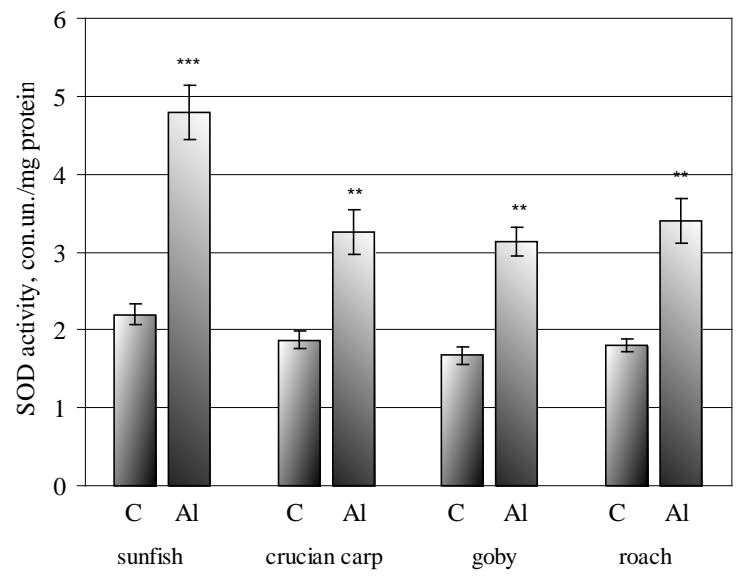

Fig. 2. SOD activity in the brain of sunfish, crucian carp, goby and roach groups treated with aluminum ions $(\mathrm{Al})$ in compared to control groups of fish (C): see Fig. 1

The analysis of glial fibrillary acid protein (GFAP) content in the brain of sunfish, goby, crucian carp and roach fish individuals exposed to $10 \mathrm{mg} / \mathrm{l} \mathrm{Al}{ }^{3+}$ displayed a significant increase in the expression of this astroglial marker in fish of all groups (Fig. 3).

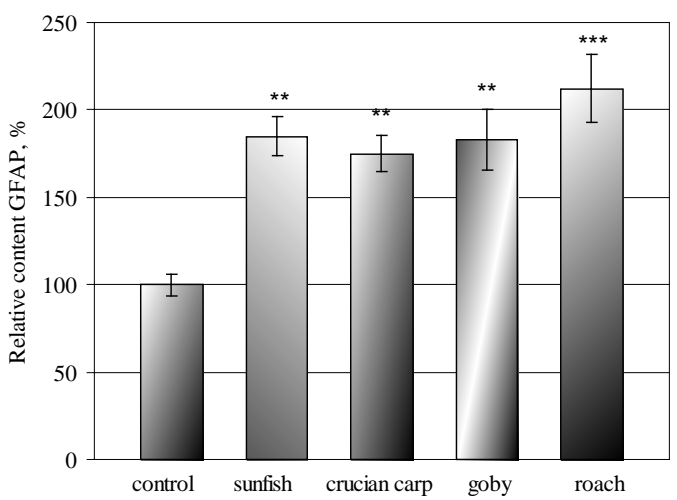

Fig. 3. Relative GFAP content in the brain of sunfish, crucian carp, goby and roach groups treated with aluminum ions $(\mathrm{Al})$ in comparison with the control groups of fish (C): see Fig. 1

The treatment of all studied fish groups induced similar changes in GFAP expression. In the experimental groups of sunfish, crucian carp, goby and roach this was higher than the control values $(\mathrm{P}<0.01)$ by $185 \%, 175 \%, 183 \%$ and $212 \%$, respectively. In the group of goby and crucian carp, aluminum ions induced a more meaningful increase in the content of GFAP compared with sunfish and roach. Such an increase in protein expression indicates the species-specific features of astroglial reactivation in response to the action of aluminum ions. These differences may be caused by various trophic and mobile activities of the investigated species of fishes. The increase in the expression of the protein of intermediate glial filaments is accompanied by the appearance of degraded polypeptide fragments of GFAP. Such 
derivatives can be identified by immunoblotting provided that their antigenic determinants are preserved in the native state. A comparative analysis of the polypeptide fragments composition of the GFAP showed a significant increase in the content of products of proteolytic degradation of the $49 \mathrm{kDa}$ intact subunit in all fish species groups.

The detected differences imply the induction of intensive processes of reorganization of the cytoskeleton of nervous tissue astrocytes in the sunfishes from all the age groups by the ions of aluminum. Growth of the expression of an astroglial marker (GFAP) under the influence of higher than normal $\mathrm{Al}^{3+}$ concentrations was also detected in adults of mature fish of all studied species (sunfish, goby, crucian carp, roach). It was established that the chronic effect of aluminum ions induced a significant $(P<0.01)$ increase in the content of GFAP in the brain of mature adults of the experimental groups of crucian carp, goby, sunfish and roach in comparison with the control group on average by $75 \%, 83 \%, 85 \%$ and $112 \%$ respectively. The increase in the expression of GFAP is accompanied by the appearance of degraded polypeptide fragments of this protein. The most distinctive results of immunoblotting observed for cytoskeleton fractions of fish brain proteins extracted from the control and experimental groups are shown in Figure 4.

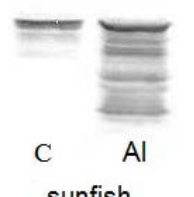

sunfish

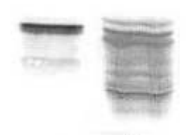

C Al

crucian carp

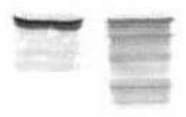

C Al goby

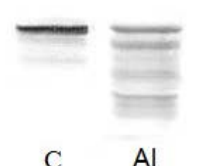

roach

Fig. 4. Western blot results of the cytoskeletal fractions of the brain proteins from sunfish, crucian carp, goby, roach inhabiting water with chronic aluminum exposure (Al): $\mathrm{C}$ - control groups of fish

Comparative study of the water-soluble and cytoskeletal GPAP fractions from the experimental and control groups showed that the insoluble subunits of this protein, being the part of the cytoskeletal structures, are subject to proteolytic degradation to a greater extent. Thus, $\mathrm{Al}^{3+}$ ions induce not only the typical reactive response in astrocytes to metabolic disturbances, but also activate the degradation of the cytoskeleton molecular components in the nervous tissue of all the above-mentioned species of various age groups.

A number of cell processes, including migration of GFAP-positive cells, largely depends on the $\mathrm{Ca}^{2+}$ intake into the cell. At the same time, the regulation of $\mathrm{Ca}^{2+}$ intracellular concentration is carried out by means of calcium-binding proteins universal for all cell types. One type of such proteins is the neurospecific protein $\mathrm{S} 100 \beta$, synthesized predominantly by neuroglia cells. It was found that prolonged exposure to aluminum chloride induces a significant increase in the cytosolic protein $\mathrm{S} 100 \beta$ content in the fish brain. A comparative analysis of the immunoblotting results, which allows one to evaluate the differrences in the content of the $\mathrm{S} 100 \beta$ protein in the brains of mature adults of the sunfish and crucian carp in experimental and control groups, suggests a significant increase in the content of polypeptides with a molecular weight range from 24 to $37 \mathrm{kDa}$ (Fig. 5).

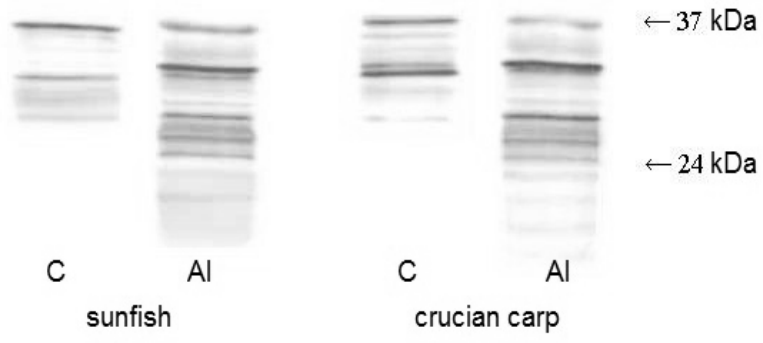

Fig. 5. Western blot results of cytosolic fractions of brain proteins of sunfish and crucian carp treated with aluminum ions (Al): C - control groups of fish

The content of this protein significantly increased in the fish brain of the experimental groups, namely: the sunfish (on average 105\%, $\mathrm{P}<0.05$ ) and crucian carp (67\% on average, $\mathrm{P}<0.01$ ) with respect to similar indices concerning the fish brain of the same control group species. The results of our study prove that intoxication with aluminum ions causes the response of molecular transformations in astroglial cells of the neural tissue. In the process of such changes an increase in the synthesis of the cytoskeletal GFAP is accompanied by a significant increase in the content of the cytosolic calcium-binding protein S100 $\beta$ and its derivatives with $\mathrm{Mr}=24-37 \mathrm{\kappa Da}$. These findings showing toxicity of aluminum ions for nervous tissue cells of fishes are completely consistent with current ideas about its potential neuro- toxicity for a wide range of organisms (Gostomski, 1990). Our study shows that oxidative stress is closely associated with the development of reactive astrogliosis in the nervous tissue of fish from various pelagic zones. Aluminum ions induce the upregulation of both GFAP and protein $\mathrm{S} 100 \beta$ expression and also stimulate the proliferation and differentiation of astrocytes in the brains of various fish species. The most intensive astroglial reactivation was detected in the brains of mature fishes. At the same time, an increase in the content of LPO final products in the brains of individuals from this experimental group was lower than in other age groups. The research results indicate the important role of astrocytes in protecting nervous tissue during intoxication. The age-related differences in the intensity of astrogliosis indicate that young adults have the highest level of adaptive potential and the more pronounced ability of astrocytes to proliferate in the brains of fishes in the first half of ontogeny.

Data on the neurotoxic effect of aluminum are very limited. Exposure of salmon to $\mathrm{Al}$ in an acidic environment induced an elevation of plasma cortisol and glucose levels, which is a sign of physiological stress. The expression of $\mathrm{NeuroD}_{1}$ transcript level was reduced as well as neural plasticity. Together these disturbances may impair the ability to adapt in various environments (Grassie et al., 2013). Al-induced toxicity was evaluated with $0.1 \mathrm{mg} / \mathrm{l}$ which accords to the maximum concentration allowed in order to protect aquatic organisms. Despite the low dose oxidative stress characteristics were determined such as LPO increase and moduation of SOD activity as well as neurotoxicity - rising of dopamine and adrenaline levels (Fernandez-Davila et al., 2012).

These results are in accord with the data obtained while using other fish species. The treatment of carp (Cyprinus carpio) with various aluminum doses displayed genotoxic and cytotoxic effects on the lymphocytes. Moreover, the authors found significant increase in the amount of DNA damage which is related to $\mathrm{Al}^{3+}$ ions concentration and duration of the exposure. The modification of DNA was accompanied with a growth of oxidized DNA level as well as cell cycle disturbances and activation of apoptosis (García-Medina et al., 2011).

The results of our studies allow us to conclude that the effect of aluminum ions on the nervous tissue of fish from various pelagic zones induces the occurrence of oxidative stress. As a result of oxidative disorders in the neural tissue, a cellular response is realized, namely the reactivation of astrocytes, which is accompanied by molecular transformations resulting in an increase in the expression of such astrocyte-specific proteins as GFAP and S100 $\beta$ protein. The increase in the synthesis of the cytoskeletal GFAP is closely associated with a significant increase in the content of the cytosolic calcium-binding protein S100 $\beta$ and its derivatives. The complex evaluation of astrogliosis indices (content of GFAP and S100ß) and oxidative stress under the conditions of effect of aluminum ions can be used as valid biomarkers to assess the state of fish from various 
pelagic zones during ontogenesis. The results obtained demonstrate significant polypeptide heterogeneity of GFAP. The most representative spectrum of degraded polypeptide fragments is found in the brains of fish treated with aluminum ions. Such heterogeneity is most likely to be the consequence of the destabilization of filament structures due to intensive rearrangement of intermediate filaments. Synthesized de novo, soluble polypeptides of GFAP can be actively included in such cytoskeletal rearrangements. Balance between synthesis of new subunits of GFAP and proteolysis of pre-existent cytoskeleton fibrils is extremely important for essential cellular functions, especially proliferation, migration, and regulation of cell reactivity (Tykhomyrov et al., 2016).

Earlier, it was demonstrated that the dynamic properties of intermediate filaments is associated with the exchange of subunits between pools of the soluble fraction and polymerized fibrils. Modern ideas demonstrate another way of restructuring filaments, i.e. through the limited proteolysis of their proteins under the influence of damaging factors. Proteolysis of filament proteins can be caused by an increase in the degree of their phosphorylation and an increase in the concentration of $\mathrm{Ca}^{2+}$ ions. Excessive phosphorylation of GFAP induces the destruction of the glial filament network during mitosis (Eng et al., 2000). With an increase in the concentration of calcium ions in the cell, degradation of the polypeptides of GFAP in situ can affect the $\mathrm{Ca}^{2+}$-dependent calpain II proteinase, while the native protein is split into a series of polypeptides with a molecular weight in the range of 28-47 kDa (Nedzvetsky et al., 1991).

The nature of the glial response depends largely on both the nature of the damaging factors and the duration of the exposure: mechanical damage to the central nervous system induces rapidly increasing astrogliosis (Suzuki et al., 2012), and processed by-products of oil and aluminum ions cause a slower astroglial reaction (Nedzvetskii et al., 2006; Sukharenko et al., 2017). At the same time, various factors can cause similar astroglial reactivity. The maximum intensity of the astroglial response to critical damage coincides in time with the intensive death of cells in the nervous system (Ben Haim et al., 2015).

The brain forms a huge number of afferent and efferent pathways, connecting the central nervous system with peripheral organs. Nerve cells are considered to be a sensitive indicator of fish responses to the combined effects of toxins. This is due to the fact that the brain takes an active part in the formation of reflex reactions of fish with changing environmental conditions. The excitation that occurs during such reactions spreads rapidly throughout the body and can lead to loss or deterioration of the reflexes of balance, decreased muscle tone, deterioration of locomotor and many other physiological processes. The state of intermediate filaments of astrocytes is one of the reliable indicators of the plasticity of the properties of the nervous system. Astrocytes show the highest ability to react to the influence of unfavorable environmental factors, protect neurons and ensure their viability.

In many cases of neurodegenerative pathologies, biochemical signs of oxidative stress are present simultaneously with functional and structural disorders of proteins. Oxidative stress is one of the most common and main inducers of structural and functional disorders in the nervous tissue under the conditions of unfavourable factors of physical and chemical nature as well as metabolic disorders.

The results show that research on the effect of anthropogenic pollution substances with diverse chemical nature on the fishery value of water bodies cannot be performed only by studying common used oxidative stress data. Moreover, the state of the cytoskeleton of glial cells reflects a toxic anthropogenic affect and indicates the long-term benefits of using GFAP as a molecular marker of the toxic affect of environmental factors. The effects of modern environmental pollutants require complex study, which should combine the characteristics of both biochemical and molecular biomarkers. Integrated data on the biomarkers could be fruitful in detecting abnormal changes at the late stages of intoxication, at the level of irreversible changes. To recognize them earlier, it is necessary to use biochemical methods, since metabolic processes and molecular rearrangements form the basis of adaptive reactions of the organism.

\section{Conclusions}

The conparative analysis of results of research on the effects of aluminum ions on astrocyte reactivity, generation of oxidative stress in both the brain and liver of fishes from various pelagic areas permits one to observe the similar characters of both neuro- and hepatotoxicity of aluminum ions. Accordingly the data obtained on the content of POL final, show that aluminum ions induce more intense oxidative damage in neural tissue (in 1.5-2.0 times) in comparison with liver samples of fishes.

The chronic effect of aluminum chloride $(10 \mathrm{mg} / \mathrm{L})$ induces increase in expression of intermediate filament protein of astrocytes GFAP (on 75-112\%) and cytosole calcium-bind protein S100 $\beta$ (by 67$112 \%)$. The growth of the synthesis of these markers is an index of astrocyte reactivity as a response to the neurotoxic effect of aluminum.

The neurotoxic effect of aluminum is associated with the increase of the content of proteolytic degradation products of both GFAP and protein $\mathrm{S} 100 \beta$, which was determined in a range of molecular mass 40-49 and 24-37 kDa, respectively.

The proliferation and the migration of astrocytes are one of key mechanisms which provide the neural system function in conditions of stress induced by toxicants. The integrated measurement of the indexes of astrogliosis (GFAP, S100 $\beta$ content) coupled with the index of oxidative stress under the effect of aluminum ions could be used as valid biomarker to assess the state of fishes from various pelagic areas polluted with industrial waste.

\section{References}

Aksu, A. J. (2015). Sources of metal pollution in the urban atmosphere (A case study: Tuzla, Istabul). Journal of Environmental Health Science and Engineering, 13, 79 .

Ben Haim, L., Carrillo-de Sauvage, M. A., Ceyzériat, K., \& Escartin, C. (2015). Elusive roles for reactive astrocytes in neurodegenerative diseases. Frontiers in Cellular Neuroscience, 9, 278.

Cardwell, A. S., Adams, W. J., Gensemer, R. W., Nordheim, E., Santore, R. C., Ryan, A. C., \& Stubblefield, W. A. (2017). Chronic toxicity of aluminum, at a $\mathrm{pH}$ of 6, to freshwater organisms: Empirical data for the development of international regulatory standards/criteria. Environmental Toxicology and Chemistry, in print.

Driscoll, C. T. (1985). Aluminum in acidic surface waters: Chemistry, transport, and effects. Environmental Health Perspectives, 63, 93-104.

Eng, L. F, Ghirnikar, R. S., \& Lee, Y. L. (2000). Glial fibrillary acidic protein: GFAP-thirty-one years (1969-2000). Neurochemical Research, 25(9-10), 1439-1451.

Fernandez-Davila, M. L., Razo-Estrada, A. C., García-Medina, S., GomezOlivan, L. M., Pinon-Lopez, M. J., Ibarra, R. G., \& Galar-Martinez, M. (2012). Aluminum-induced oxidative stress and neurotoxicity in grass carp (Cyprinidae - Ctenopharingodon idella). Ecotoxicology and Environmental Safety, 76(2), 87-92.

Garcia-Medina, S., Razo-Estrada, C., Galar-Martinez, M., Cortez-Barberena, E., Gomez-Olivan, L. M., Alvarez-Gonzalez, I., \& Madrigal-Bujaidar, E. (2011). Genotoxic and cytotoxic effects induced by aluminum in the lymphocytes of the common carp (Cyprinus carpio). Comparative Biochemistry and Physiology C: Toxicology and Pharmacology, 153(1), 113-118.

Gillmore, M. L., Golding, L. A., Angel, B. M., Adams, M. S., \& Jolley, D. F. (2016). Toxicity of dissolved and precipitated aluminium to marine diatoms. Aquatic Toxicology, 174, 82-91.

Gostomski, F. (1990). The toxicity of aluminum to aquatic species in the US. Environ Chemistry Health, 12(1-2), 51-54.

Grassie, C., Braithwaite, V. A., Nilsson, J., Nilsen, T. O., Teien, H. C., Handeland, S. O., Stefansson, S. O., Tronci, V., Gorissen, M., Flik, G., \& Ebbesson, L. O. (2013). Aluminum exposure impacts brain plasticity and behavior in Atlantic salmon (Salmo salar). Experimental Biology, 216(16), 3148-3155.

Grassie, C., Braithwaite, V. A., Nilsson, J., Nilsen, T. O., Teien, H. C., Handeland, S. O., Stefansson, S. O., Tronci, V., Gorissen, M., Flik, G., \& Ebbesson, L. O. (2013). Aluminum exposure impacts brain plasticity and behavior in Atlantic salmon (Salmo salar). Journal of Experimental Biology, 216(16), 31483155.

Liu, S., Noth, E. M, Dixon-Ernst, C., Eisen, E. A, Cullen, M. R, \& Hammond, S. K. (2014). Particle size distribution in aluminum manufacturing facilities. Environmental Pollution, 4(3), 79-88.

Miller, G. L. (1959). Protein determination for large numbers of samples, Analytical Chemistry, 31(5), 964-966. 
Nedzvetskii, V. S., Kirichenko, S. V., Baydas, G., \& Nerush, O. P. (2012). Effects of melatonin on memory and learning deficits induced by exposure to thinner. Neurophysiology/Neirofiziologiya, 44(1), 42-48.

Nedzvetskii, V. S., Tuzcu, M., Yasar, A., Tikhomirov, A. A., \& Baydas, G. (2006) Effects of vitamin $\mathrm{E}$ against aluminum neurotoxisity in rats. Biochemistry (Moscow), 71(3), 239-244.

Nedzvetskiy, V. S., \& Nerush, P. O. (2011). Hyperthyreosis effects on the learning, memory and glial intermediate filaments of a rat brain. Physiology and Pathophysiology, 2, 269-278.

Nedzvetsky, V. S., Ushakova, G. A., Busigina, S. G., Berezin, V. A., \& Dvoretsky, A. I. (1991). Effect of low-level radiation on intermediate filaments and Ca-activated proteolysis in rat brain. Radiobiology (Moscow), 31(3), 333-339.

Ohkawa, H. (1979). Assay for lipid peroxides in animal tissues by thiobarbituric acid reaction. Analytical Biochemistry, 95(2), 351-358.

Pereira, S., Cavalie, I., Camilleri, V., Gilbin, R., \& Adam-Guillermin, C. (2013). Comparative genotoxicity of aluminium and cadmium in embryonic zebrafish cells. Mutation Research, 750(1-2), 19-26.

Singla, N., \& Dhawan, D. K. (2015). Modulation of (14) C-labeled glucose metabolism by zinc during aluminium induced neurodegeneration. Neuroscience Research, 93(9), 1434-1441.

Sivakumar, S., Khatiwada, C. P., \& Sivasubramanian, J. (2012). Bioaccumulations of aluminum and the effects of chelating agents on different organs of Cirrhinus mrigala. Environtal Toxicology and Pharmacology, 34(3), 791-800.
Skilbrei, O. T., Finstad, B., Urdal, K., Bakke, G., Kroglund, F., \& Strand, R. (2013). Impact of early salmon louse, Lepeophtheirus salmonis, infestation and differences in survival and marine growth of sea-ranched Atlantic salmon, Salmo salar L., smolts 1997-2009. Fish Diseases, 36(3), 249-260.

Sukharenko, E. V., Nedzvetsky, V. S., \& Kyrychenko, S. V. (2017). Biomarkers of metabolism disturbance in bivalve molluscs induced by environmental pollution with processed by-products of oil. Biosystems Diversity, 25(2), 113-118.

Sun, J. J., Liu, Y., \& Ye, Z. R. (2008). Effects of $\mathrm{P}_{2} \mathrm{Y}_{1}$ receptor on glial fibrillary acidic protein and glial cell line-derived neurotrophic factor production of astrocytes under ischemic condition and the related signaling pathways. Neuroscience Bulletin, 24(4), 231-243.

Suzuki, T., Sakata, H., Kato, C., Connor, J. A., \& Morita, M. (2012). Astrocyte activation and wound healing in intact-skull mouse after focal brain injury. European Journal of Neuroscience, 36(12), 3653-3664.

Trenfield, M. A., Markich, S. J., Ng, J. C., Noller, B., \& van Dam, R. A. (2012) Dissolved organic carbon reduces the toxicity of aluminum to three tropical freshwater organisms. Environmental Toxicology and Chemistry, 31(2), 427-436.

Tykhomyrov, A. A., Pavlova, A. S., \& Nedzvetsky, V. S. (2016). Glial fibrillary acidic protein (GFAP): On the 45th anniversary of discovery. Neurophysiology (Springer), 48(1), 54-71.

Walton, R. C., McCrohan, C. R., Livens, F., \& White, K. N. (2010). Trophic transfer of aluminium through an aquatic grazer-omnivore food chain. Aquatic Toxicology, 99(1), 93-99. 